\title{
Perceptions Of Customers Regarding Their Expectations Of Service Quality In South African Full-Service Restaurants
}

\author{
Petro Naudé, LISOF, South Africa \\ Sharon Rudansky-Kloppers, University of South Africa, South Africa
}

\begin{abstract}
Full-service restaurants serve different types of customers with preconceived ideas about what they want and expect to receive from the restaurant. During the dining experience, each customer experiences the service differently and subconsciously evaluates the experience differently. The purpose of this research is to determine the expectations and perceptions of customers regarding service quality sub-dimensions at Full-Service Restaurants (FSRs). A selfadministered survey of employees at a tertiary academic institution revealed that waiter professionalism, lack of individual attention, long waiting periods and stock-outs in FSRs are the most important concerns when it comes to the expectations of service quality. The findings of this study analysed a demographic profile (gender, age, home language, highest education qualification, LSM groups) and it was found that demographic category groups differ in the way that they perceive service quality. The study reveals that males tend to be less critical than women, LSM 9 respondents are less critical than LSM 10 respondents and respondents with an undergraduate degree or less are less critical than respondents with a post-graduate degree. The study also reveals a strong correlation between service quality and customer satisfaction. Recommendations include that management must focus on pricing strategies, strategic marketing, waiter training and the flow of communication between the restaurant and the customer. The recommendations made in this study will assist management of FSRs to understand the significance of high-quality service and to implement the required levels of service quality. With this knowledge, the management of FSRs can be assured of a satisfied customer and a competitive offering.
\end{abstract}

Keywords: Service Quality; Customer Satisfaction; Full-Service Restaurants; Gauteng; South Africa

\section{INTRODUCTION}

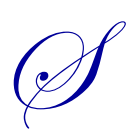

trong competition in the Food and Beverage industry has made it increasingly important for owners and managers of Full-Service Restaurants (restaurants that provide waiter table service) to have a competitive advantage in the industry. One way to gain this advantage is through excellent service quality (Kandampully, Mok \& Sparks, 2001:112). Service quality is a subjective evaluation of the service made by the customers of the full-service restaurant (FSR). Once FSR owners and managers have knowledge of what their customers perceive as important in the service quality process, they can ensure customer satisfaction and acquire this competitive advantage. Although an FSR has a wide variety of customers, this study mainly focuses on the upper segments of society who visit FSRs (SAARF, 2014), namely LSM 9 and LSM 10.

Knowledge of these customers' expectations and perceptions of service quality will enable management to satisfy better the customers' needs and wants and in return increase their own bottom line and competitive standing.

When customers visit an FSR, they have preconceived ideas about the service quality they want and expect to receive. These are their expectations of service quality. It is important to differentiate between the service expectations and the service perceptions that a customer has. Service expectations is defined as "a combination of customers' predictions about what is likely to happen during the service transaction" (Reimann, Lunemann \& Chase, 2008:64). Then, during the service encounter, each customer will also experience the service differently and they will subconsciously evaluate the service quality. These are a customer's service perceptions. Service perceptions can 
be defined as a customer's "global judgements or attitudes, which relate to the superiority of a service" (Reimann et al., 2008:64). Therefore, service quality $=$ service perceptions + service expectations.

In this study service quality sub-dimensions are examined in order to understand what customers' expectations and perceptions of service quality in a FSR is and whether it will lead to customer satisfaction. In the next section the research problem is discussed.

\section{RESEARCH PROBLEM}

Although there is a profusion of studies carried out on the dimensions discussed in this study, there is a lack of previous research in the Food and Beverage industry in South Africa. By understanding the significance of the dimensions and implementing the required dimensions, management can capitalise on a growing profit margin due to higher customer satisfaction. The need exists to refine the theories and models to describe the South African environment.

\section{LITERATURE BACKGROUND}

Knowing what the customer expects is a very important step in delivering a service of high quality. If the management of FSRs do not know what customers expect, they can lose the customers' business as well as money and resources (Wilson, Zeithaml, Bitner \& Gremler, 2008:56). Based on the model in Figure 1 below, there are four levels of customer expectations, ranging from acceptable expectations, experience-based expectations, normative 'should' expectations to ideal expectations and desires.

Figure 1. Levels of expectations

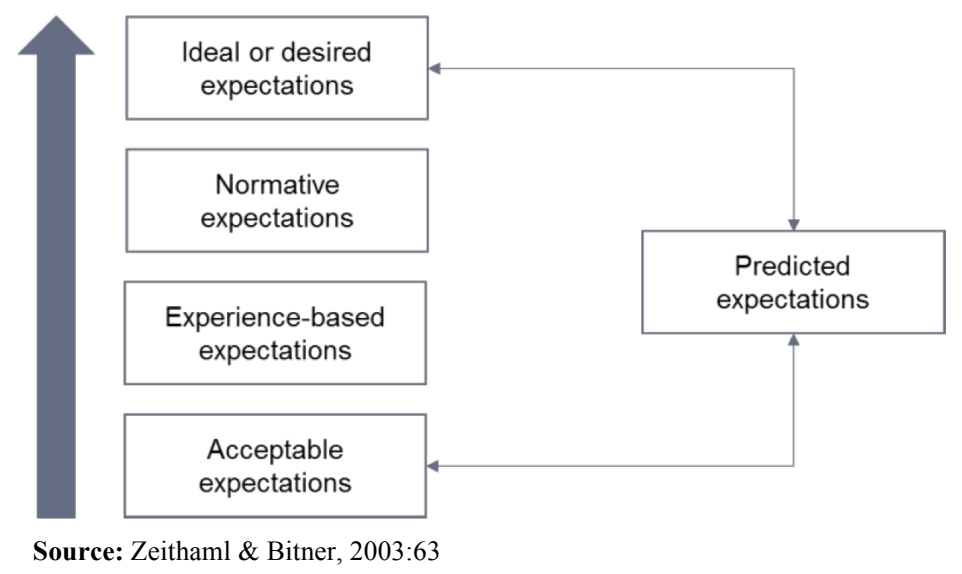

The desired level of service is the service that the customer hopes to receive (Wilson et al., 2008: 58). This level is a blend of what the customer believes "can be" and "should be" done, as displayed in Figure 1. The customer's desired expectation may be the food that is moderately priced and the service which is offered in a relaxed atmosphere. Normative expectations represent what a customer thinks should happen - for example, at an expensive FSR, they will expect to receive service to match the price (Zeithaml \& Bitner, 2003:63). Experience-based expectations refer to when a customer's past experiences at the specific FSR shapes the expectations (Zeithaml \& Bitner, 2003:63). For example, in the past the service may have been a bit slow, so the customer will expect slow service again.

Alongside experience-based expectations are acceptable expectations, which indicate the minimum level of service that the customer will tolerate before being dissatisfied (Zeithaml \& Bitner, 2003:63). For example, if a customer knows that the restaurant delivers good service in normal conditions, he will accept a slightly slower service if he perceives that the restaurant is very busy. Another example is that a customer will accept a less desired seat in a restaurant on Valentine's Day, just because he really wants to visit that specific restaurant on that day. The predicted level of service represents the customer's concrete service expectation and this expectation can range from the ideal service to the adequate service level (Zeithaml \& Bitner, 2003:63). 


\section{Factors That Influence Customer Expectations of Service Quality at FSRS}

Since this research focuses on customer expectations of service quality at FSRs, this section provides a brief background of factors that influence expectations. Customer expectations can originate from three basic factors: namely, internal factors, external factors and situational factors (Kasapila, 2006:12). Internal factors include personal needs, philosophies of service and lasting past experiences. External factors comprise of the social context and word-of-mouth recommendations. Situational factors such as reasons for eating out, the weather and time constraints will also impact customers' expectations of the service quality at FSRs. All of these factors will ultimately contribute to how the customer predicts the service to be. This predicted service is an estimate of the service that the customer will receive in the next service encounter. It differs from desired and acceptable service expectations in the sense that these levels are global assessments, whereas predicted service is only of the next upcoming service encounter. These predictions are likely to be more concrete and specific than expectations of desired and adequate services (Wilson et al., 2008:64).

Demographic factors such as gender, language, LSM level, race and level of education could also influence expectations. The effect of these demographical factors on service quality was investigated in the study. For each customer these factors will differ and will have a different influence on the evaluation that they make of the service, but it is important to understand that not all customers will evaluate a service in the same way or with the same criteria. In the following section the sub-dimensions of service quality are discussed.

\section{Service Quality}

Studies show that service has become the leading element of the global economy over the last three decades (Cao, Townsend \& Daniel, 2010:2). A service can be seen as a type of performance, as each encounter allows the FSR's personnel to perform actions and activities of value to the customer (Durvasula, Lyonski \& Subbash, 2005:15). Kotler (2005) defined service as 'any behaviour or act based on contact between two parties: the provider and the receiver, and the essence of this reciprocal process is intangible (Prasad \& Shekhar, 2010:88).

When visiting an FSR, customers experience anxiety about service quality as they feel they have little or no control. This feeling may be attributed to uncontrollable service settings or due to employees' motivational levels (Weiermar, 2000: 398). It is important to manage employees and make management decisions to reduce this anxiety. At times, customers may even experience a mixture of service failure and service delight, which highlights the fact that evaluating service quality is personal and subjective (Sivakumar, Li \& Dong, 2014: 52). There are three broad perspectives on service quality: namely, the product-orientated perspective, the user-orientated perspective and the value-orientated perspective. The product-orientated perspective sees service quality as the function of the discrepancy between the actual and ideal attributes of a product or service. The user-orientated perspective sees quality as the ability of a product or service to satisfy human needs and the value-orientated perspective sees quality as the difference between benefits and costs.

For the purpose of this research, service quality is defined as an overall, subjective (Chang, 2009:166, Shaikh, 2009:178) judgement or appraisal (Lee, Park, Park, Lee \& Kwon, 2005:30) of the superiority of the product or service (Parasuraman in González, Comesaña \& Brea, 2007:153-160) made by the customer regarding the excellence of a service (Weaver, Weber \& McCleary, 2007:335) and the degree and direction of the difference between expected, perceived and delivered service qualities (Shonk \& Chelladurai, 2008:589; Kim, Ng \& Kim, 2009:10-17). Due to the various expectations of the customer and the delivery of the service, gaps can open up in the service delivery process. These gaps are illustrated in the SERVQUAL Model, which is shown in Figure 2. This model provides an integrated framework for managing service quality and customer-driven service innovation (Bitner, Zeithaml \& Gremler, 2010: 198). The primary goal of the model is to meet or exceed customer expectations. If customer expectations are exceeded, it will lead to customer satisfaction. Customer satisfaction is defined as the pleasurable, emotional psychological state (Shaikh, 2009:178) a customer experiences as a result of the appraisal of a service (Westbrook \& Michael in Seidman, 2000:55) when it meets or exceeds the customer's expectations (Seidman, 2000:56). This judgment from the customer is not a static one, but is a dynamic, moving target that may evolve over time. 
Figure 2. SERVQUAL Gaps Model

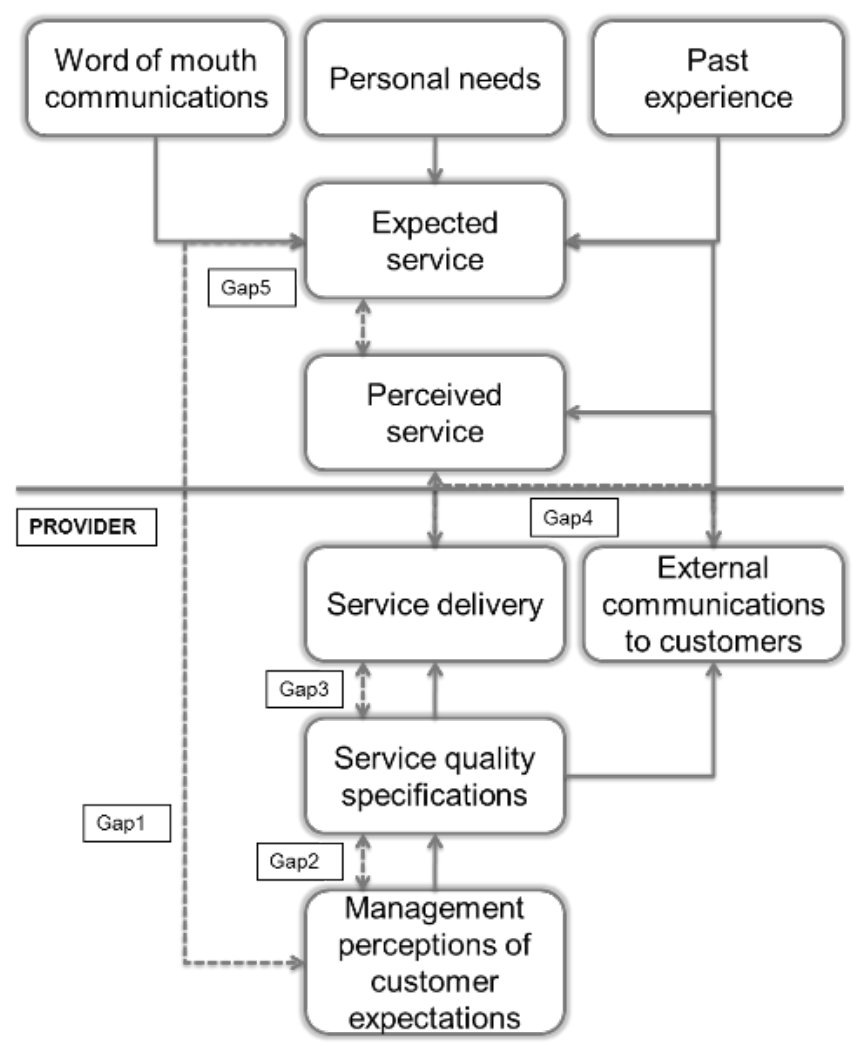

Source: Adapted from Hang \& Bradley, 2002

The SERVQUAL model identified five gaps. Gaps 1 to 4 lie within the control of the management of the FSR and can be used to analyse the causes of Gap 5 and to identify ways of reducing the gap. Therefore, Gap 5 relates to the customers' perceptions and expectations (Soita, 2012:264). This study does, however, not concentrate on the gaps, but only measures customer expectations and perceptions of service quality by looking at the five dimensions of service quality as derived from SERVQUAL, namely reliability, responsiveness, assurance, empathy and tangibility. This approach was also followed by Manwa (2011), who used these five SERVQUAL dimensions to determine whether Botswana restaurants meet customers' expectations.

Reliability refers to the ability to perform the promised service dependently and accurately (Fick \& Ritchie in Seidman, 2000:10). This means that the FSR will deliver on its promises. Reliability may be characterised by accurate reservations of tables and accurate billing (Kasapila, 2006:35). Responsiveness is the willingness to help customers and provide prompt service (Fick \& Ritchie in Seidman, 2000:10). Responsiveness is communicated to customers by the length of time they have to wait to be served, attention to problems or answers to questions. If customers are assisted timeously, the quality of the service will be improved. Assurance is defined as the knowledge and courtesy of employees and their ability to convey trust and confidence (Fick \& Ritchie in Seidman, 2000:10). Assurance is especially important if customers are uncertain about certain aspects of the service offering. An example will be if a waiter can give confident recommendations about the menu items. Empathy is defined as the caring, individualised attention the business provides to its customers (Fick \& Ritchie in Seidman, 2000:10). In a restaurant setting, it is important to make the customers feel as if they are receiving personal attention. They want to feel understood and believe that someone is attending to their needs. Empathy can be shown by addressing the customer by his/her name if the customer is in the same peer group, or by addressing the customer's personal needs (Kasapila, 2006:36). Tangibility is defined as the appearance of physical facilities, equipment, personnel and communication materials (Mohsen, 2005:52). If the tables are clean, the menus clear and neat and the bathrooms tidy, it will complement the intangible service and contribute to a higher quality of service. In the following sections the research objectives and research methodology is discussed. 


\section{RESEARCH OBJECTIVES}

The main purpose of the study was to determine the expectations and perceptions of customers regarding FSR dining experience dimensions. The secondary objectives were (A) to determine the expectations perceived to be important in the dimensions of the dining experience by customers in FSRs; (B) to determine customers' perceptions of the service quality received in a specific FSR; (C) to determine if a relationship exists between the service quality sub-dimensions and customer satisfaction and (D) to investigate the behaviours of customers in different demographic groups regarding their expectations and perceptions of the dining experience dimensions. A better understanding of these factors should give management guidance as to what customers expect to receive at their restaurants.

\section{RESEARCH METHODOLOGY}

To achieve the overall objective of the study, the five sub-dimensions of service quality were investigated. These are empathy, assurance, reliability, responsiveness and tangibility. Expectations of service quality were measured by asking respondents to indicate which sub-dimension they considered the most important amongst the service quality sub-dimensions. Respondents were also asked to give their perceptions regarding each of the items within each subdimension of the service quality at an FSR they recently visited.

Both primary and secondary research was conducted for this study. For the secondary research, a literature review was conducted. The purpose of the literature study was to obtain a broad overview of the customers' expectations and perceptions of the service quality sub-dimensions. If significant influences were noted in previous research, a foundation was laid for this study that made it easier to reach the objectives of the study. The primary research involved quantitative research that involved the collection of primary data from individuals in order to project the results to the population of Gauteng.

\section{Sampling}

The target population for this research consists of educators at a tertiary academic institution in Gauteng. Gauteng province was chosen because it contributes more than $33 \%$ to the economy and $10 \%$ to the GDP of Africa (Rudansky-Kloppers, 2014:1188). The units of analysis are the individual educators. Fifty-six educators worked at this institution at the time of the study. Educators of the tertiary education institution were chosen because the majority of professional and managerial individuals are LSM 9 and 10 (TV South Africa, 2010), which indicates a broad knowledge of marketing concepts and experience at food service providers.

As the population is small and the database of the population could be obtained, a census was used and no sampling thus applies. A census is defined as a count of all the elements in a population (Zikmund \& Babin, 2007:90). According to Cooper and Schindler (2008: 375), a census is feasible when the population is small, and it is necessary when the elements are quite different from one another. The size of the population of the tertiary academic institution suggests that a census was feasible.

\section{Data Collection}

Data were collected during one month of thirty days. The lengthy period (one month) enabled the researcher to maximise the eliciting of information from participants. Respondents were made aware of the questionnaire by emails that were sent to them. No incentives were offered for the completion of the questionnaire. The research process was conducted according to strict ethical standards. Ethical considerations included, among others, an informed consent form that was signed by respondents as well as a confidentiality agreement with respondents.

The process for collecting the data was as follows: The questionnaire was pre-tested on individuals to ensure content validity. In the pre-test participant interest, question transformation, questionnaire length, the continuity and flow of the questionnaire and the question sequence were tested and the questionnaire was adapted accordingly. The final questionnaire was delivered in hard copy to the institution and emailed to all of the lecturers in the Pretoria campuses. As lecturers completed the questionnaires, they either gave them to the secretary, who scanned and 
emailed the completed questionnaires to the researcher or they emailed the completed questionnaires directly to the researcher. All of the data were captured and coded on Excel.

\section{Construct Validity and Reliability}

Construct validity was determined by subjecting each dimension to principal component analysis. The five subdimensions of service quality were subjected to principal component analysis to determine if each represents a single construct. A measure is reliable to the degree that it supplies consistent results (Cooper \& Schindler, 2008: 292). When a questionnaire provides reproducible results, the measuring instrument is reliable (Zikmund \& Babin, 2007:210). The Kaiser-Meyer-Elkin Measure of Sampling Adequacy was above 0.751 for all of the sub-dimensions, which is above the threshold value of 0.5 and the Bartlett's Test of Sphericity which was significant $(p=0.000)$ for all of the sub-dimensions, which indicated that a factor analysis is appropriate. The analysis indicated the existence of one construct for all the sub-dimensions, except for empathy, which indicated two constructs based on the eigenvalue criterion (Eigen value $\geq 1$ ) which explained $64.85 \%$ of the variance. The constructs were renamed empathy - individual attention (refers to staff remembering customers and securing a table for them) and empathy humanic clues (refers to staff greeting customers pleasantly and that staff were caring and attentive). The analysis generated a clear factor structure for all of the sub-dimensions. The final factor loadings for the dimensions are shown in Table 1 below.

Table 1. Factor Loadings:

\begin{tabular}{|c|c|c|c|}
\hline Sub-dimension & Statements & Factor1 & Factor2 \\
\hline \multirow{4}{*}{ Empathy } & Staff greeted you pleasantly. & 0.772 & \\
\hline & Staff were caring and attentive. & 0.751 & \\
\hline & Staff secured a table for you. & & 0.802 \\
\hline & Staff remembered/ knew you. & & 0.801 \\
\hline \multirow{5}{*}{ Responsiveness } & Waiters took your order promptly. & 0.727 & \\
\hline & The manager was willing to assist customers. & 0.711 & \\
\hline & The service was fast/quick. & 0.689 & \\
\hline & Staff were willing to serve customers. & 0.681 & \\
\hline & Waiters drew your attention to dishes that were on special. & 0.634 & \\
\hline \multirow{4}{*}{ Assurance } & Staff were polite and understanding. & 0.887 & \\
\hline & Waiters knew the menu items to help customers. & 0.807 & \\
\hline & Waiters served food in a professional way. & 0.805 & \\
\hline & Staff were friendly or courteous. & 0.500 & \\
\hline \multirow{4}{*}{ Tangibility } & The table was clean. & 0.844 & \\
\hline & Staff were wearing proper attire. & 0.844 & \\
\hline & The restaurant was tidy. & 0.706 & \\
\hline & Staff were clean/neat. & 0.706 & \\
\hline \multirow{4}{*}{ Reliability } & Staff provided the correct change. & 0.854 & \\
\hline & Staff provided an accurate bill. & 0.833 & \\
\hline & Required food/beverage items were in stock. & 0.669 & \\
\hline & The restaurant is always open and has long hours of operation. & 0.377 & \\
\hline
\end{tabular}




\section{EMPIRICAL RESULTS AND RECOMMENDATIONS}

The overall findings relating to the demographic profile of respondents are summarised as in Table 2 below.

Table 2. Demographic profile of respondents

\begin{tabular}{l|l|c}
\hline \multicolumn{1}{c}{ Demographic variable } & \multicolumn{1}{c}{ Majority category } & Category Percentage \\
\hline Age & $18-30$ & $53 \%$ \\
\hline Gender & Female & $67 \%$ \\
\hline Language & Afrikaans & $82 \%$ \\
\hline Level of Education & Undergraduate Degrees & $41 \%$ \\
& Honours Degrees & $41 \%$ \\
\hline Race & White & $94 \%$ \\
\hline LSM group & LSM 10 & $80 \%$ \\
\hline
\end{tabular}

As can be seen in Table 2 on the previous page, the major age group was $18-30$ years (53\%) and most of the respondents were white (94\%), Afrikaans (82\%), females (67\%) and in the LSM 10 segment (80\%). Most respondents do have a tertiary education $(81 \%)$. In the sections to follow the results regarding the expectations and perceptions of service quality are discussed.

\section{Expectations of Service Quality}

This section aimed to address the following secondary objective: (A) to determine the expectations perceived to be important in the dimensions of the dining experience by customers in FSRs. In the questionnaire respondents identified the most important aspect regarding their expectations from the following options: (1) the overall appearance of facilities (tangibility), (2) employees providing prompt service (responsiveness), (3) employees who are always willing to help (empathy), (4) employees who are knowledgeable about the products and services offered (reliability) and (5) employees who are professional (responsiveness). The results indicated that respondents regard employees who are professional as the most important aspect regarding their expectations of service quality (25\%). Twenty-three percent of the customers $(23 \%)$ also regard employees who provide prompt service as the most important aspect. Therefore, responsiveness is seen as the most important sub-dimension with regards to the expectations of service quality.

\section{Perceptions of Service Quality}

This section aimed to address the following secondary objective: (B) to determine customers' perceptions of the service quality received in a specific FSR. The perceptions of customers were analysed according to the five SERVQUAL sub-dimensions: empathy, responsiveness, tangibility, reliability and assurance. The main results on this topic conclude that respondents agreed that the FSRs rated satisfactory in these sub-dimensions of the dining experience. Most respondents were in agreement that staff greet customers pleasantly, but respondents felt that there was a lack of individual attention. Respondents were of the opinion that staff are willing to help customers, but they fail to draw attention to the specials. Staff are prompt and professional, but they do not have a good knowledge of the menu items. The respondents agreed that the tangible aspects of the FSRs were of good quality. In Figure 3 a summary of service quality perceptions can be seen. 
Figure 3. Service quality perceptions

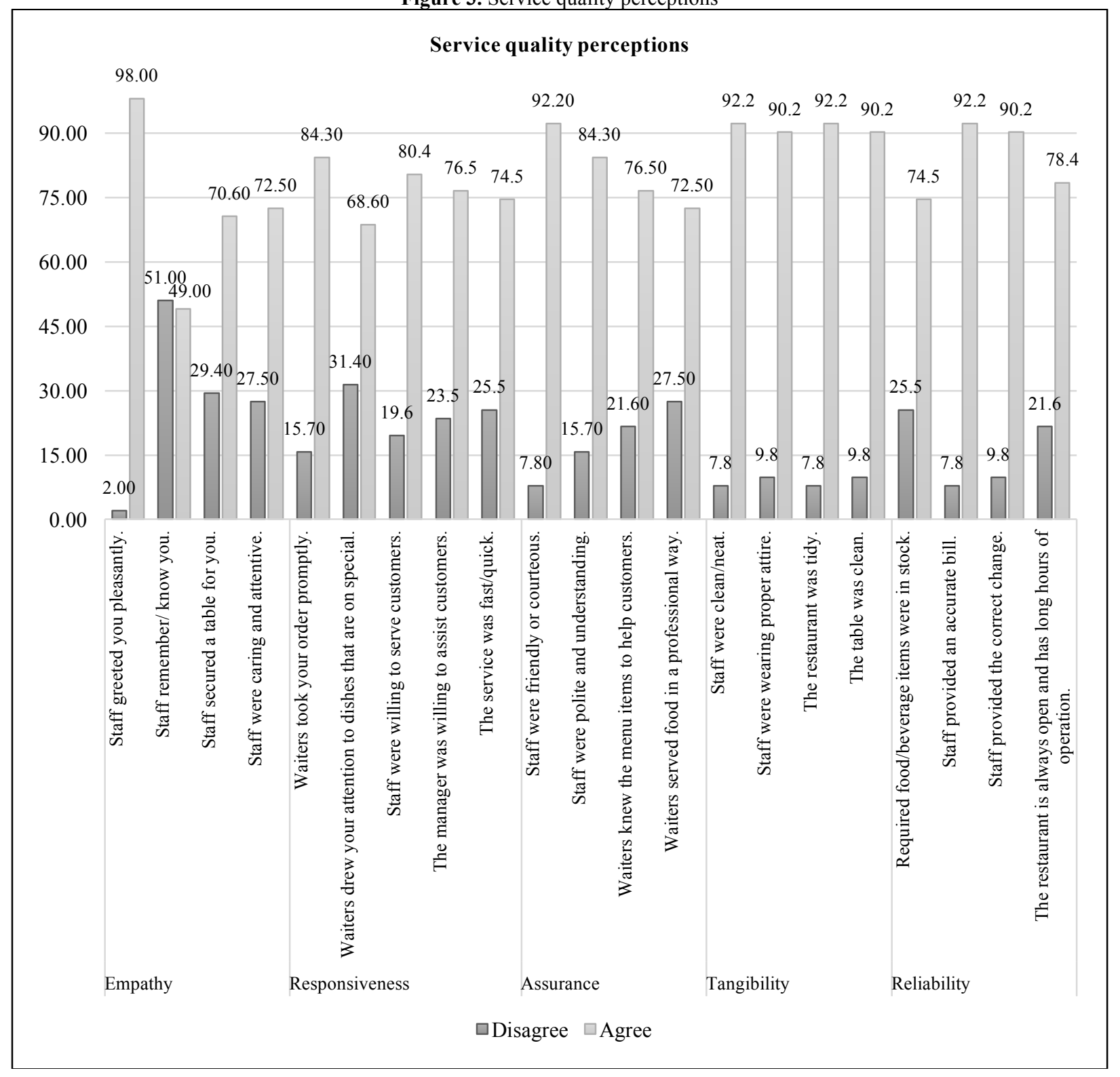

\section{Perceptions of Empathy}

Staff can show empathy by caring and individualised attention to customers. In a restaurant setting, it is important to make the customers feel as if they are receiving personal attention. The main results on this topic conclude that staff greet the customers pleasantly (98\%). Just over half of the respondents (51\%) were neutral or disagreed that the staff remember them. This can be due to high waiter turn-over or that customers do not often visit the same restaurant. Another reason can be that the study was done in a major city and hundreds of patrons visit the restaurants, which can make it difficult for staff to remember every customer that visit their restaurant. More than a quarter of the respondents were neutral or disagreed that staff were caring and attentive $(27.5 \%)$ and that the staff did secure a table for them $(29.4 \%)$. Just over half of the respondents $(51 \%)$ were neutral or disagreed that they received individual attention from the waiters. These results showed that, although staff greet the customers pleasantly, the respondents felt a lack of individual attention from the staff. The recommendation for FSRs in Gauteng is to invest time and money in training the staff to be more attentive to the individual needs of customers. 


\section{Perceptions of Responsiveness}

Responsiveness refers to promptness and the willingness of staff to help customers. Important factors are the waiting time for service, the staff's attention to customers' problems and the knowledge that staff have to answer customers' questions. The main results on this topic conclude that most respondents were in agreement that staff are responsive to their needs. Most respondents were in agreement that waiters took orders promptly $(84.3 \%)$ and that the staff were willing to serve them quickly (74.5\%). However, almost two-thirds (68.6\%) of the respondents were neutral or disagreed that staff drew their attention to the dishes that are on special. These results showed that staff are willing to help the customers and that they respond promptly, but they fail to draw attention to specials.

The recommendation for FSRs in Gauteng is to place more focus on the specials, either by stand-up advertisements on the tables or posters. A good idea might be to have a breast-pin for waiters stating: "Ask me about the special of the day." This will remind the waiter to tell the customers about the specials and also draw the customer's attention to the fact that the restaurant has specials. Another aspect that waiters always have to work on is the promptness of service. The waiting period between dishes can be reduced through constant communication with the customer, which will reduce the uncertainty regarding the service.

\section{Perceptions of Assurance}

Assurance is when the staff convey trust, knowledge and confidence when working with the customers. Assurance reduces the uncertainty regarding aspects of the dining experience. The main results on this topic conclude that the majority of respondents were in agreement that staff were friendly or courteous $(92.2 \%)$, polite and understanding $(84 \%)$ and that the food was served in a professional way $(72.5 \%)$. However, the last percentage indicates that $27.5 \%$ of the respondents were neutral or in disagreement that the food was served in a professional way, which indicates the need to increase the professionalism of the service. One aspect of concern is that $21.6 \%$ of the respondents were in disagreement or neutral that waiters know menu items and could help them with the dishes. As the waiter is the link between the customer and the restaurant, the waiter should have knowledge of the ingredients in the dishes and the variety of dishes available. A knowledgeable waiter will, for example, inform customers of allergens in dishes. These results showed that customers experienced the staff as polite and professional, but felt that they have a lack of knowledge about the dishes.

The recommendation for FSRs in Gauteng is to include regular assessment of menu knowledge in their waitertraining programmes. Knowledge of the menu will increase the professionalism of the service and also assure customers that their waiters are knowledgeable. Another recommendation could be to include a large amount of information regarding dishes on the menu, such as the seasonal price, nutritional information and possible allergens.

\section{Perceptions of Tangibility}

Tangibility refers to the appearance of physical facilities, equipment, personnel and communication materials. Although the tangibles do not relate directly to the food or the service at an FSR, it has a major indirect impact on the way that customers experience the restaurant. Stained menus or dirty tables immediately send out a message of a lack of professionalism. The main results on this topic conclude that a high majority of the respondents were in agreement that the tangible aspects of the dining experience were of a high standard. $92.2 \%$ of respondents were in agreement that the staff were clean/neat and that the restaurant was tidy and $90.2 \%$ were in agreement that the staff were wearing proper attire and that the tables were clean. These results thus showed that customers experienced the tangible elements as satisfactory. Although the feedback from respondents was positive, FSRs must maintain high standards concerning the tangibles of the dining experience. Staff inspections must regularly be held to ensure that they are wearing the correct attire and to ensure personal hygiene. The restaurant must be cleaned on a regular basis, with frequent inspections.

\section{Perceptions of Reliability}

Reliability refers to the ability of the staff to perform the service as promised in communication with customers. Important aspects include the accuracy of the bill and change, as well as whether the restaurant is always open 
during advertised business hours. The main results conclude that the respondents were in agreement that the bill provided was accurate $(92.2 \%)$, that the correct change was provided $(90.2 \%)$ and that the restaurant was open when they wanted to visit the restaurant (78.4\%). One aspect of concern was that a quarter of the respondents $(25.5 \%)$ were neutral or disagreed that the required food and beverage items were in stock. These results indicate that customers are satisfied with the billing process and the business hours, but that stock-outs are a concern.

The recommendation for FSRs in Gauteng is to ensure that no stock-outs occur. If, however, stock-outs are inevitable, the situation must be communicated to customers before orders are placed. This can be done by noticeboards in the restaurant indicating which menu items will not be available. These notice-boards should be updated as soon as an ingredient is out of stock, or almost out of stock. The waiter should also inform the customers in their welcoming message. Another recommendation is to communicate the operating hours of the restaurant in notices outside the restaurant or on advertisements and on their website, to avoid disappointment.

\section{Means of Service Quality}

Factor-based scores were calculated for each sub-dimension as the mean score of the variables included in each factor for each respondent. The main results conclude that the majority of the respondents were in agreement regarding the service quality sub-dimensions, as most of the means are above 3.5, except for empathy - individual attention. The reason for this may be that customers want to receive personalised attention from the staff. Some interesting findings include:

- The over-60 group has a higher overall rating of the statements, as all of the means are above 4, which may indicate that they are less critical regarding the service aspect.

- Overall, males are less critical than females when analysing service quality sub-dimensions, as the males' means are higher overall than those for females.

- Race groups differ in the way they evaluate service quality sub-dimensions. Black respondents are more agreeable with the empathy sub-dimensions and responsiveness, while white respondents tend to agree more with tangibility (mean $=4.4$ ) and assurance sub-dimensions (mean $=4.2)$ and coloured respondents agree more with regarding reliability $($ mean $=4.5)$.

\section{The Relationship between Service Quality Sub-Dimensions and Customer Satisfaction}

This section aimed to address the following secondary objective: (C) to determine if a relationship exists between the service quality sub-dimensions and customer satisfaction. To determine whether a statistically-significant relationship exists between the service quality sub-dimensions and customer satisfaction the Pearson correlation coefficient was calculated for each pair of variables and tested for statistical significance. All the correlation coefficients were above 0.75 and statistically significant at a $1 \%$ level of significance. See Table 3 below which shows the correlation between customer satisfaction and the service quality sub-dimensions.

Table 3. Correlation between customer satisfaction and service quality sub-dimensions

\begin{tabular}{|c|c|c|c|c|c|c|c|c|}
\hline \multicolumn{9}{|c|}{ Correlations } \\
\hline & & $\begin{array}{c}\text { Overall } \\
\text { perception }\end{array}$ & Tangibility & Reliability & Assurance & Responsiveness & $\begin{array}{c}\text { Empathy: } \\
\text { Humanic } \\
\text { Clues }\end{array}$ & $\begin{array}{l}\text { Empathy: } \\
\text { Individual } \\
\text { Attention }\end{array}$ \\
\hline \multirow{3}{*}{$\begin{array}{c}\text { Overall } \\
\text { perception }\end{array}$} & $\begin{array}{l}\text { Pearson } \\
\text { Correlation }\end{array}$ & 1 & $.858^{* *}$ & $.835^{* *}$ & $.882^{* *}$ & $.872^{* *}$ & $.858 * *$ & $.746^{* *}$ \\
\hline & $\begin{array}{l}\text { Sig. } \\
\text { (2-tailed) }\end{array}$ & & .000 & .000 & .000 & .000 & .000 & .000 \\
\hline & $\mathrm{N}$ & 51 & 51 & 51 & 51 & 51 & 51 & 51 \\
\hline
\end{tabular}

** Correlation is significant at the 0.01 level (2-tailed).

This result indicates a very strong relationship between each of the service quality sub-dimensions and customer satisfaction. Therefore, it can be concluded that when the service quality aspects are at a satisfactory level, the customer will be satisfied overall with the experience. This is a very important aspect, as the aim of any business is to satisfy the needs of the customer to get their business in return. 


\section{Differences between Demographic Groups Concerning Service Quality}

This section aimed to address the following secondary objective: (D) to investigate the behaviours of customers in different demographic groups regarding their expectations and perceptions of the dining experience dimensions. The Mann-Whitney test and the Kruskal-Wallis test were used to test the relationship between the service quality subdimensions and demographic groups. Concerning age, gender, language and education groups, no statistical differences were found concerning the service quality sub-dimensions. However, race groups differ in the way they evaluate service quality sub-dimensions and between the LSM 9 and LSM 10 groups a statistically-significant difference was found concerning the tangibility sub-dimension. LSM 10 respondents tend to agree more concerning the tangibility aspect than LSM 9 respondents, which indicate that the appearance of the facilities and staff is more important to LSM 10 respondents than to LSM 9 respondents.

The mean ranks further indicate that:

- There are no significant differences between gender or race groups. The over-60 group tend to agree more with regard to responsiveness, empathy - humanic clues and empathy - individual attention.

- English respondents tend to agree more regarding service quality, as the mean ranks for the English respondents are higher than those for Afrikaans respondents.

- Respondents with an undergraduate degree or less tend to agree more regarding service quality than respondents with postgraduate degrees.

- LSM 9 group tends to agree more with the dimension of tangibility than the LSM 10 group.

- LSM 10 group tends to agree more with both the empathy sub-dimensions than the LSM 9 group.

Table 4 below indicates the results of LSM groups and service quality.

Table 4. LSM groups and Service Quality

\begin{tabular}{l|c|c|c|c|c|c}
\hline & Tangibility & Reliability & Assurance & Responsiveness & $\begin{array}{c}\text { Empathy: } \\
\text { Humanic } \\
\text { Clues }\end{array}$ & $\begin{array}{c}\text { Empathy: } \\
\text { Individual } \\
\text { Attention }\end{array}$ \\
\hline Mann-Whitney U & 67.50 & 120.5 & 106 & 114 & 87.5 & 82.5 \\
\hline Asymp. Sig. (2-tailed) & 0.71 & 0.936 & 0.644 & 0.733 & 0.244 & 0.19 \\
\hline Exact Sig (2(1-tailed)) & $0.77^{\mathrm{b}}$ & $0.938^{\mathrm{b}}$ & $0.667^{\mathrm{b}}$ & $0.792^{\mathrm{b}}$ & $0.265^{\mathrm{b}}$ & $0.202^{\mathrm{b}}$ \\
\hline Mean Rank LSM 9 & 33.25 & 23.58 & 25.83 & 22.50 & 18.08 & 17.25 \\
\hline Mean Rank LSM 10 & 22.65 & 24.06 & 23.15 & 24.22 & 24.87 & 24.99 \\
\hline
\end{tabular}

The results indicate that there is a statistical difference, at the $10 \%$ level of significance between the LSM 9 and LSM 10 groups with regards to their perception of service quality. Furthermore, the mean ranks indicate that the LSM 9 group tend to agree more with the dimension of tangibility (mean rank $=33.25$ ) than the LSM 10 group (mean rank $=22.65)$. The results also indicate that the LSM group tend to agree more with both the empathy subdimensions (mean ranks $=24.87$ and 24.99) than the LSM 9 group (mean ranks $=18.08$ and 17.25). Management of FSRs should keep this in mind when designing the market offering. If the focus is on LSM 9, more effort must be made to improve the appearance of the restaurant and staff, but if the focus is on LSM 10, more effort should be made to create a personalised service for each customer.

\section{CONCLUSION AND RECOMMENDATIONS}

The overall aim of the research was to analyse the service quality expectations and perceptions of customers at FSRs. The aim was to gain a better understanding of the dimensions within service quality and to understand what is important to customers. It can be concluded that the research study succeeded in its objectives and that the study successfully analysed the perceptions and expectations of service quality of customers at FSRs.

Furthermore, the research has led to a better understanding of the unique needs of customers when it comes to the sub-dimensions of service quality. This information can be utilised by the management of FSRs when planning the dining experience. It was found that employee professionalism (assurance), lack of individual attention (empathy), long waiting periods (responsiveness) and stock-outs (reliability) are some of the most important concerns with service quality. It was also found that demographic groups differ in the way that they evaluate the dining experience. 
Overall, males tend to be less critical than women regarding all of the service quality sub-dimensions; LSM 9 respondents are less critical than LSM 10 respondents and respondents with an undergraduate degree or less are less critical than respondents with a postgraduate degree when evaluating service quality. Management must work on pricing strategies, strategic marketing, waiter training and assessment and the communication between the restaurant and the customer. By incorporating the above-mentioned elements within their strategic management plans, FSRs should be able to meet customer needs, ensuring a satisfied customer and a competitive offering.

\section{AUTHOR BIOGRAPHIES}

Petro Naudé is a lecturer in business management at LISOF. She holds a MCom degree in Business Management and has been lecturing at various institutions for 4 years. Her research interests include hospitality, customer service, consumer behaviour, marketing and business management.

Sharon Rudansky-Kloppers is an Associate Professor in the Department of Business Management at The University of South Africa (Unisa). She holds a DCom degree in Business Management and has been lecturing at Unisa for 27 years. Her research interests include business management, consumer behaviour, marketing and business communication.

\section{REFERENCES}

Bitner, M., Zeithaml, V.A. \& Gremler, D.D. (2010). Technology's Impact on the Gaps Model of Service Quality. Retrieved from: http://www.gremler.net/personal/research/2010_Technology_in_Services_in_IBM_Handbook.pdf.

Cao, Y., Townsend, K. \& Daniel, P. (2010). Service Quality Comparison of Franchising and L- Licensing Units within the Same Brand from the Customer Perspective. Retrieved from:

http://scholarworks.umass.edu/cgi/viewcontent.cgi?article=1166\&context=gradconf_hospitality\&seiredir $=1 \&$ referer $=\mathrm{http} \% 3 \mathrm{~A} \% 2 \mathrm{~F} \% 2 \mathrm{Fscholar}$.google.co.za.

Chang, J. (2009). Taiwanese Tourists' Perceptions of Service Quality on Outbound Guided Package Tours: A Qualitative Examination of the SERVQUAL Dimensions. Journal of Vacation Marketing, 15(2), 165.

Cooper, D.R.I \& Schindler, P.S. (2008). Business research methods. 10th ed. New York: McGraw-Hill.

Durvasula, S., Lyonski, S. \& Subbash, C.M. (2005). Service Encounters: The Missing Link Between Service Quality Perceptions and Satisfaction. The Journal of Applied Business Research, 21(5):15-20.

González, M.E.A., Comesaña, L.R. \& Brea, J.A.F. (2007). Assessing Tourist Behavioral Intentions through Perceived Service Quality and Customer Satisfaction. Journal of Business Research, 60(2), 153-160.

Hang, H. \& Bradley, G. (2002). Measuring the Performance of IT Services: An Assessment of SERVQUAL. International Journal of Accounting Information Systems, 3, 151-164.

Kandampully, J., Mok, C. \& Sparks, B. (2001). Service Quality Management in Hospitality, Tourism \& Leisure. New York: The Haworth Hospitality Press.

Kasapila, W. (2006). Young adults' satisfaction regarding their dining experience in casual dining restaurants in Hatfield, Pretoria. Dissertation (Master's in Food Science). University of Pretoria.

Kim, W.G., Ng, C.Y.N. \& Kim, Y. (2009). Influence of Institutional DINESERV on Customer Satisfaction, Return Intention and Word-Of-Mouth. International Journal of Hospitality Management, 28(1), 10-17.

Kotler, P., Bowen, J.T., \& Makens, J.C. 2005. Marketing For Hospitality and Tourism. 4th ed. New Jersey: Pearson Education.

Lee, Y., Park, H., Park, D., Lee, K.A. \& Kwon, Y. (2005). The Relative Impact of Service Quality on Service Value, Customer Satisfaction, and Customer Loyalty in Korean Family Restaurant Context. International Journal of Hospitality and Tourism Administration, 6(1), 27-51.

Manwa, H. (2011). Do Botswana's restaurants meet customers' expectations? African Journal of Marketing Management, 3(1):14-21.

Markovic, S., Raspor, S. \& Segaric, K. (2010). Does Restaurant Performance Meet Customers' Expectations? An Assessment of Restaurant Service Quality Using a Modified DINESERV Approach. Tourism and Hospitality Management, 16(2), 181-195.

Mohsin, A. 2005. Service Quality Perceptions: An Assessment of Restaurant and Café Visitors in Hamilton, New Zealand. The Business Review, 3(2), 51-57.

Prasad, M.D. \& Shekar. B.R. (2010). A Service Quality Scale for Measuring Indian Railway Passenger Services. Management Science and Engineering, 4(3): 87-94.

Reimann, M., Lunemann, U.F. \& Chase, R.B. (2008). Uncertainty Avoidance as a Moderator of the Relationship between Perceived Service Quality and Customer Satisfaction. Journal of Service Research, 11(1), 63-73.

Rudansky-Kloppers, S. (2014). Investigating Factors Influencing Customer Online Buying Satisfaction In Gauteng, South Africa. International Business \& Economics Research Journal, 13(5): 1187-1198. 
SAARF. (2014). Census and AMPS. Retrieved from: www.saarf.co.za. [Accessed: 20 May 2014].

Seidman, A.M. (2000). An examination of the relationship between employee behaviour and customer satisfaction in quick service restaurants. Dissertation (Master's in Marketing Management). University of Pretoria.

Shaikh, U.A.A. (2009). Impact of Restaurant Quality on Customer Satisfaction: Evidence from the Restaurant Industry in Pakistan. The Business Review, 13(2), 178-185.

Shonk, D.J. \& Chelladurai, P. (2008). Service Quality, Satisfaction, and Intent to Return in Event Sport Tourism. Journal of Sport Management, 22, 587-602.

Sivakumar, K., Li, M. \& Dong, B. (2014). Service Quality: The Impact of Frequency, Timing, Proximity, and Sequence of Failures and Delights. Journal of Marketing, 41(78), 41-58.

Soita, P.W. (2012). Measuring Perceived Service Quality Using SERVQUAL: A Case Study of the Uganda Health and Fitness Sector. International Journal of Business and Social Science, 3(5):261-271.

TV South Africa. (2010). TV South Africa. Retrieved from: http://www.tvsa.co.za/default.asp?blogname=news\&artic leID $=4931$

Weaver, A., Weber, K. \& McCleary K.W. (2007). Resort Evaluation: The Role of Previous Travel Experience and Trip Characteristics. Journal of Travel Research, 45(3), 333.

Weiermair, K. (2000). Tourists' Perceptions Towards and Satisfaction with Service Quality in the Cross-Cultural Service Encounter: Implications for Hospitality and Tourism Management. Managing Service Quality, 10(6), 397-399.

Wilson, A., Zeithaml, V., Bitner, M. \& Gremler, D.D. (2008). Services Marketing: Integrating Customer Focus across the Firm. McGraw-Hill: Europe.

Zeithaml, V.A. \& Bitner, M.J. (2003). Services Marketing: Integrating Customer Focus Access to the Firm. 3rd ed. New York: McGraw-Hill.

Zikmund, W.G. \& Babin, B.J. (2007). Essentials of Marketing Research. 3rd ed. Mason OH: Thompson. 


\section{NOTES}

